\title{
Is the Corporation Tax an Effective Automatic Stabilizer?
}

Michael P. Devereux Centre for Business Taxation,

Saïd Business School, University of Oxford, Oxford OX1 1HP

\section{Clemens Fuest}

Centre for Business

Taxation,

Saïd Business School, University of Oxford, Oxford OX1 1HP

\section{National Tax Journal Vol. LXII, No. 3 September 2009}

\begin{abstract}
We investigate the extent to which the corporation tax can act as an automatic stabilizer by smoothing the effects on investment of shocks to income. The main stabilizing effect would be through a reduced tax liability affecting the internal funds available for investment by credit-constrained companies. We present evidence for the United Kingdom that most credit-constrained firms have also been likely to be in a tax loss-making position, implying that the tax does not smooth investment, and thus is not an effective automatic stabilizer. A more generous treatment of tax losses would introduce significantly more automatic stabilization.
\end{abstract}

\section{INTRODUCTION}

$\mathrm{T}$ he current recession has renewed interest in the extent to which the tax system acts as an automatic stabilizer, dampening the shocks hitting the economy. The main mechanism by which a tax can have such an effect is by inducing smaller shocks to post-tax income, which in turn may result in smaller effects on aggregate demand, especially through smoothing of consumption and investment.

The degree of stabilization depends on two factors. The first is the degree to which shocks to gross income are translated into shocks to net income. This depends primarily on the rate of tax. In the extreme case, a tax with a marginal rate of 100 percent would imply that net income would be unaffected by shocks to gross income. It also depends on the symmetry of the tax system. A proportional tax would induce the same percentage change in net income as in gross income. A progressive tax with several marginal rates would, in aggregate, be anti-cyclical, in the sense that the average marginal tax rate would tend to fall when income falls and would tend to rise when income rises. This provides a greater cushioning effect of the shocks hitting gross income than a proportional tax.

The second factor is the impact of changes to net income on the components of aggregate demand, notably consumption and investment. If the shock to income is regarded as temporary, and if consumption depends on a notion of permanent income, then shocks to net income may not affect consumption patterns. However, smoothing consumption 
over the cycle may require individuals to borrow to pay for current consumption. Individuals who are unable to borrow will find that current consumption depends directly on net income. For this group, the impact of the tax system over the cycle may be an important determinant of consumption patterns. If the proportion of the population facing such credit constraints is large, then the degree to which taxes reduce shocks to net income can be important for the impact of shocks on consumption.

Auerbach and Feenberg (2000) investigated the automatic stabilizing properties of taxes on the income of individuals in the United States, identifying over a long period how the tax system cushioned shocks to gross income, and estimating the impact on consumption. They found that there has been relatively little change in the role of the U.S. federal tax system as an automatic stabilizer since the early 1960s. Their central estimate is that tax-induced consumption responses offset 14 percent of the initial shocks to gross income. Since gross income is approximately 57 percent of GDP, this is equivalent to a stabilization effect of 8 percent of the initial shocks to GDP.

This paper extends the work of Auerbach and Feenberg to consider the automatic stabilizing properties of the corporation tax. At first glance and compared to the personal income tax, the potential for automatic stabilization through the corporate income tax seems smaller because corporate income tax revenue is much smaller. But this neglects the fact that income in the form of corporate profit tends to be more affected by the business cycle (i.e., it is more volatile than other types of income) in particular labor income. The most obvious route by which shocks to GDP are offset through the corporation tax is by smoothing corporate investment. As with the impact of personal taxes, this involves two components. The first is the extent to which shocks to gross corporate income are translated into shocks to net corporate income, after corporation tax. The second is the extent to which shocks to net corporate income are translated into effects on capital expenditure. This paper analyses each of these effects.

After the corporate tax rate, the most important aspect of the tax for its effect on net corporate income is the treatment of taxable losses. This is because even corporation taxes which appear to be proportional, in the sense that they have only one declared statutory tax rate, typically do not give full relief for losses. In the absence of full loss relief, there are effectively two rates which can apply in a given period: the statutory rate and zero. ${ }^{1}$ When faced with a shock which reduces gross income but leaves the company with a positive corporate income tax base, the effects of the tax are generally symmetric. For example, at a tax rate of 30 percent, a fall of $\$ 100$ in gross income leads to a $\$ 70$ fall in net income, while a rise in gross income of $\$ 100$ leads to a $\$ 70$ rise in net income. In either case, the change in net income is 70 percent of the change in gross income. But if the negative shock leads to a loss, which does not generate an immediate tax rebate, then the fall in tax will be smaller than 30 percent of the shock to gross income. Hence the fall in net income will be greater than 70 percent of the fall in gross income.

Relative to a proportional tax, this creates a pro-cyclical effect. On average the tax rate falls in a recession, and rises in a boom. While the decline of the tax rate in

\footnotetext{
1 The present value of losses carried forward to future periods can be positive, suggesting that the effective tax rate can lie between zero and the statutory rate. However, in the context of credit constraints on investment, the relevant rate is the one which applies in each period.
} 
a recession would have a stabilizing effect compared to a strictly proportional tax if incomes were positive, it would have a destabilizing effect if incomes were negative. This does not mean that the tax has no stabilizing role, since changes to net income will typically still be smaller than changes to gross income. But its value as an automatic stabilizer is weaker than that of a proportional tax at the same rate.

The second aspect of the automatic stabilizing role is the effect on investment expenditure. In perfect capital markets, a normal forward-looking investment decision should not be affected by the availability of external financing. ${ }^{2}$ However, for firms that cannot raise external financing, investment is constrained by the availability of internal financing, that in turn is partly determined by the current tax liability. ${ }^{3}$ The investment of a firm that is credit constrained and is also in a tax loss position, is therefore determined in part by the generosity of loss relief rules. If losses can be carried back to offset taxable profits in earlier periods, then the level of losses at which the marginal tax rate becomes zero is lower than the case in which losses cannot be carried back. If at the margin, losses do not result in a tax rebate, then the marginal tax rate in the current period is zero, and the tax has no automatic stabilizing effect.

We present evidence on the likely impact of these considerations on investment expenditure in the United Kingdom. We present estimates of the extent of tax losses, and also of the extent to which companies believe that their investment expenditure is constrained by the availability of internal or external financing. Making the heroic assumption that firms that have tax losses are also more likely to be credit constrained, we estimate the proportion of UK companies in each year that face the twin problems of a tax loss and a credit constraint. Using this assumption, we estimate a simple measure of the stabilization properties of the UK corporation tax over time, comparable to the approach used by Auerbach and Feenberg (2000).

Our precise measure indicates the proportion of the effect of an initial shock to gross income on investment that is mitigated by the tax system. That is, if there was a shock to gross income $e$ that led to a reduction in investment of $x$ in the absence of taxation, and an identical shock led to a reduction in investment of $y$ in the presence of taxation, then our measure is $(x-y) / e$. Our central estimate of this measure for the United Kingdom since 1980 is less than 1 percent; that is, less than 1 percent of the initial shock to gross income is mitigated by the tax system. If there had been full relief for losses over this period, we estimate that this figure would have been 8.5 percent. Thus, the absence of full relief for losses has led to a substantial reduction in the automatic stabilizing properties of the corporation tax.

We describe this measure in more detail in the next section. We next present our estimates for the case of the United Kingdom since 1980, and the final section presents our conclusions and suggestions for future research.

\footnotetext{
2 The presence of tax losses can affect the cost of capital directly, as we discuss below. For example, capital allowances typically cannot be claimed until the company reaches a tax-paying position; they are therefore less valuable, and the cost of capital is higher. This is another way in which the tax system may act in a pro-cyclical way. This has been investigated in a number of papers, including Altshuler and Auerbach (1990), Devereux (1989), and Devereux, Keen and Schiantarelli (1994). However, we neglect this issue in this paper.

3 There is a very large empirical literature on the impact of credit constraints on investment, beginning with Fazzari, Hubbard and Petersen (1988). A review of this literature is provided by Bond and Van Reenen (2007).
} 
MEASURING THE STABILIZING EFFECTS OF CORPORATION TAX

As described above, the stabilization properties of the corporation tax depend on the proportion of firms in a tax loss position, and the proportion of firms that are credit constrained. In this section, we sketch a simple measure to give a broad assessment of how the data could be used to construct a measure of the stabilization properties of the tax.

First, we identify the proportion of companies whose investment depends on the availability of internal financing. We then estimate the proportion of these companies that pay no corporation tax at the margin, due to being in a tax loss position. For these firms, we assume that their investment is reduced by the whole of the shock to gross income. For firms that are credit constrained but pay tax at the margin, we assume that their investment is reduced by the shock to net income, which is $1-t$ times the shock to gross income, where $t$ is the statutory tax rate. ${ }^{4}$ For other firms, investment is assumed to be unaffected by the shock to gross income, on the grounds that the shock is only temporary.

Suppose that a proportion $a$ of companies are credit-constrained. In the absence of tax, a fall of $e$ in gross income, evenly distributed across companies, would result in a fall in investment of $a e$. In the presence of a proportional tax, the change in investment would be $a e(1-t)$. In this case, a measure of the automatic stabilizing property of the tax is aet. That is, the reduction in investment is aet less than would be the case in the absence of tax.

However, now suppose that a proportion $b$ of companies is in a tax loss position. Unfortunately, we do not have access to data that identifies for any firm whether it is in a tax loss position or whether it is credit constrained. We therefore have to make the following assumptions: assume that if $a>b$, then all firms that are in a tax loss position are also credit constrained, and that if $b>a$, then all firms that are credit constrained are also in a tax loss position. Given this, then if $a>b$, the effect of a shock to gross income of $e$ on investment is $(a-b)(1-t) e+b e$. Compared to the no tax case, the reduction in investment is smaller by $a e-\{(a-b)(1-t) e+$ $b e\}=(a-b) t e$. If $a<b$, then the reduction in investment is $a e$, exactly the same as in the no tax case. Combining these two terms, the stabilizing effect of investment, measured by the impact of the tax on the reduction in the investment in response to a negative shock of $e$, expressed as a proportion of the initial shock, is

Measure of stabilization $=\max \{(a-b) t, 0\}$.

Note that it is possible that $a<b$; that is, all companies that are credit constrained are also in a tax loss position. When this is the case, then the corporation tax has no automatic stabilizing properties at all.

\section{Evidence from the United Kingdom}

\section{Data Description}

We construct this measure of stabilization for the United Kingdom since 1980. We use two data sources. The first is accounting information on UK-listed companies from Datastream. Our data include information for 537 companies, and 12,241 observations, of which 10,239 observations are from 1980 or later. Using the data, Figure 1 presents three estimates of the proportion of UK-listed companies in a tax loss position. The line

\footnotetext{
4 Note that we abstract from any capital allowances that the firm can claim immediately, which would reduce the requirement for financing. This is on the grounds that there is typically a lag between the investment and the timing of tax payments, so that the reduction in tax payments due to a higher capital allowance is delayed.
} 
Figure 1. Estimates of Percentage of Firms with Tax Losses

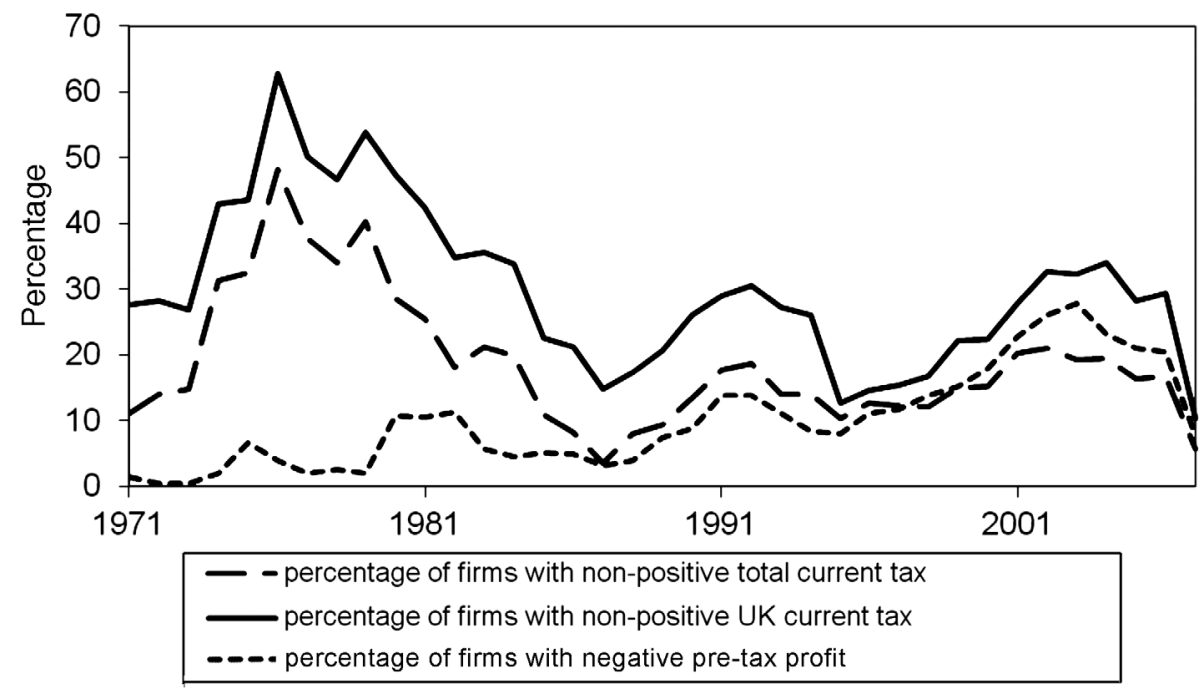

that starts at the lowest point in the early years is the proportion of companies with a negative value of pre-tax profit. The second line shows the proportion of companies estimated to have non-positive worldwide current tax liabilities, that is, it refers to the whole company, which for a multinational may include tax paid in foreign jurisdictions. It is "current" in the sense that it is an estimate of the tax actually due on current profit, excluding any tax deferred to later years. The upper line shows the proportion of companies estimated to have non-positive UK current tax liabilities.

The distinction between the latter two measures is of some interest when considering the automatic stabilizing properties of the tax. First, as is clear from the figure, a higher proportion of companies have non-positive UK tax liabilities than nonpositive worldwide tax liabilities. But second, a multinational that is credit constrained, and could increase its investment to the extent that its United Kingdom tax falls, could of course undertake that investment outside the United Kingdom. In this case, the externalities associated with the higher investment would mainly occur elsewhere.

Figure 1 confirms that the incidence of tax losses is pro-cyclical. There are increases in the proportion of firms in a tax loss position in the early 1990s, and again in the early 2000s. In the 1970s and early 1980s, the UK corporation tax had a very generous system of allowances, which meant that taxable profit was typically far below accounting profit. This accounts for the divergence between the three series in this period, with at one point well over half of the companies having a tax loss in the United Kingdom. Below we use the estimates based on the worldwide current tax and UK current tax to evaluate the stabilization properties of the tax.

The second data source is a quarterly survey taken by the Confederation of British Industry (CBI). This survey covers a range of $\mathrm{UK}$ industrial companies, and since 1980 has asked respondents to identify, "Factors likely to limit capital expenditure over the next 12 months." Options for answering this question include "internal financing" and "external financing." We take a positive answer to either 
of these questions to indicate the presence of a credit constraint. (Note that "cost of financing" is also a possible answer; we do not include those companies indicating this as a limit to their capital expenditure.)

Figure 2 presents evidence on the credit constraints for UK companies, based on the CBI survey. The proportion of firms citing internal or external financing as a constraint on investment expenditure has varied broadly between $20-30$ percent. The movements are pro-cyclical, as would be expected. Most striking are the last three points on the figure. In the most recent three quarters (beginning fall 2008), the percentage has reached an all-time high with 40 percent or more of companies facing credit constraints.

The final element of data required to construct our measure is the statutory UK corporation tax rate. This is shown in Table 1. At the beginning of the period the corporation tax rate was 52 percent. However, this was progressively reduced following the reforms in 1984 to 35 percent by 1986. By 1999 it had been further reduced to 30 percent, where it remained for the rest of the period over which we estimate our measure of automatic stabilization.

\section{Evaluating the Extent of Automatic Stabilization}

We now use the data to estimate the extent to which the UK corporation tax has acted as an automatic stabilizer, using the measure described above. Recall that we assume that the tax acts as a stabilizer to the extent that a firm is credit constrained, but is not in a tax loss position. The results are shown in Figure 3.

The lower two lines in the figure are based on the data presented above. The lower line is based on the estimates of companies with non-positive UK current tax, and the middle line is based on the estimates of companies with non-positive worldwide current tax. The very low position of the first of these lines reflects the high proportion of UK companies with non-positive UK tax liabilities. As shown in Figure 1, this was particularly high in the early part of the depicted period. However, even after this period, the proportion remained high. Clearly in many years it is higher than the proportion of UK companies identifying that investment was constrained by the availability of financing. Given the heroic assumptions made above, in those years we cannot identify any companies that faced a credit constraint yet were in a tax paying posi-

Figure 2. Percentage of Companies Citing Internal or External Finance

"Factors Likely to Limit Capital Expenditure over the Next 12 Months"

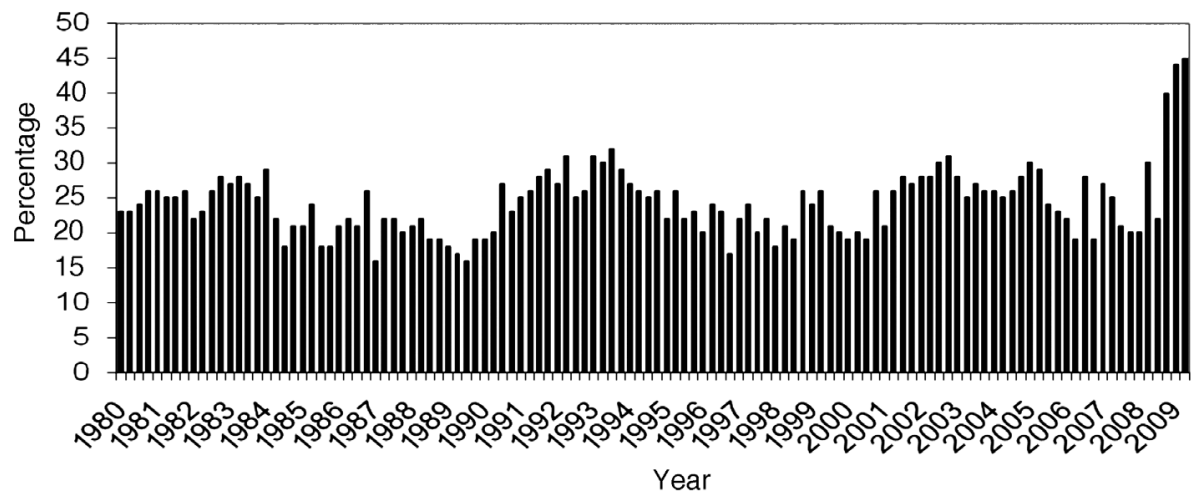

Source: CBI Industrial Trends Survey 
TABLE 1

UK CORPORATION TAX RATE, 1980-2007

\begin{tabular}{ll}
\hline 1980 & 52 \\
1981 & 52 \\
1982 & 52 \\
1983 & 50 \\
1984 & 45 \\
1985 & 40 \\
1986 & 35 \\
1987 & 35 \\
1988 & 35 \\
1989 & 35 \\
1990 & 34 \\
1991 & 33 \\
1992 & 33 \\
1993 & 33 \\
1994 & 33 \\
1995 & 33 \\
1996 & 33 \\
1997 & 31 \\
1998 & 31 \\
1999 & 30 \\
2000 & 30 \\
2001 & 30 \\
2002 & 30 \\
2003 & 30 \\
2004 & 30 \\
2005 & 30 \\
2006 & 30 \\
2007 & 30 \\
\hline &
\end{tabular}

tion. Consequently, using this approach the tax did not have any stabilizing effect: the only companies likely to be stabilized (i.e., those who faced credit constraints) also faced a zero marginal tax rate. Even in years in which the opposite was true, the proportion of firms whose investment patterns were affected by lower tax was small. On average, over the period shown, the stabilization measure is only 0.6 percent. That is, the stabilizing effect of the tax is such that less than 1 percent of the shock to gross income is mitigated by the tax.

The second line in Figure 3 shows the measure based on the worldwide current tax liability. Since this includes taxes paid in other countries, it is not entirely consistent to combine this with UK data on credit constraints and the UK tax rate. Nevertheless, for illustrative purposes, we do so since some companies may be affected by stabilization outside the United Kingdom. This measure is consistently positive after 1981, but again at a relatively low level. The average value of the measure over all the years shown is 2.9 percent.

The upper line in Figure 3 reflects a policy experiment. Suppose that the UK corporation tax system was proportional and symmetric, so that companies with taxable losses had received a rebate to offset those losses (which could be achieved in many cases with more generous loss

Figure 3. Measures of Stabilization

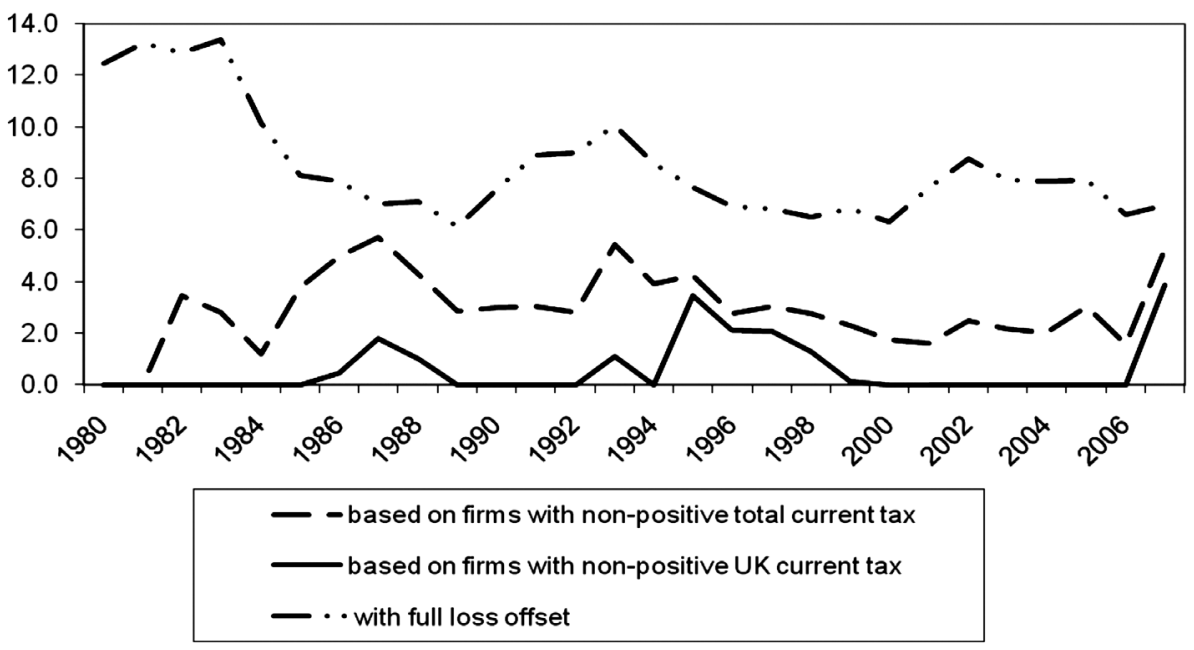


carry-back provisions). In this case, all companies that were credit constrained would be able to have higher investment expenditure relative to the no-tax case. This is equivalent in our measure of setting $b=0$, so that the measure simply becomes $a t$.

This provides a significant contrast with the actual system. In the early part of the period, the measure is around 13 percent. Subsequently it falls, but remains at around 6-8 percent. In fact, its average value over the period is 8.5 percent. This is somewhat below the results of Auerbach and Feenberg (2000) for the income tax, who found that tax-induced consumption responses amounted to 14 percent of the initial shock to gross income.

The difference between this figure and the 0.6 percent stabilization measure based on UK taxable losses is striking. Essentially, over the last 30 years the UK corporation tax has not acted as a source of automatic stabilization, in terms of affecting the investment of credit-constrained companies. Yet it would have provided an offsetting effect of over 8 percent of the initial shock had losses been treated symmetrically with profits.

\section{CONCLUSIONS}

This paper has attempted to provide a rough estimate of the extent to which the UK corporation tax acts as an automatic stabilizer. Since other countries have similar systems of corporation tax, similar effects are likely to be found elsewhere as well.

This paper finds that the UK corporation tax had virtually no automatic stabilizing impact on investment in the last three decades. Given the scale of the current recession, and the need to stimulate investment spending, that is troubling. The UK government has recently introduced a temporary measure (for two years) allowing losses up to $£ 50,000$ to be carried back to set against profits within the last three years. However, that is a very small measure.

This paper has not set out to draw policy conclusions about the design of the corporation tax. However, it provides estimates of the stabilizing properties that the tax would have had if profit and losses had been treated symmetrically. In this case, over 8 percent of a potential shock to corporate income would be offset by the tax system.

Of course, a tax system with full loss offset would come with a significant revenue cost-essentially all of the additional investment generated would be financed by paying rebates for tax losses. Paying such rebates also raises issues of fraud and the potential inducement of greater risk-taking as well as less effort. However, all these are already factors with respect to new projects undertaken by companies in a tax paying position.

It is important to see our results in the light of the strong assumptions we have made. In particular, we have abstracted from the fact that both the risk of facing credit constraints and the likelihood to be affected by shocks differs across firms. Also, firms that face the risk of being credit constrained in the future may take this into account in times when they are not constrained. In addition, we have made two assumptions on the coincidence of credit constraints and tax losses. First, if the number of firms with credit constraints is higher than the number of firms with tax losses, all firms who are in a tax loss position also face credit constraints. Second, if the number of firms with tax losses is higher than the number of credit constrained firms, all firms who are credit constrained are also in a tax loss position. Investigating the validity of these assumptions requires linking data on credit constraints with accounting data. This is a fruitful avenue for future research. 


\section{Acknowledgment}

This paper was prepared for the Spring 2009 meeting of the National Tax Association, in Washington D.C., May 21-22, 2009. We are grateful to Thiess Buettner and Peter Merrill for helpful comments, and to Simon Loretz and the CBI for the provision of data. We acknowledge financial support from the ESRC under grant RES-060-25-0033.

\section{REFERENCES}

Altshuler, Rosanne, and Alan J. Auerbach.

"The Significance of Tax Law Asymmetries: An Empirical Investigation." Quarterly Journal of Economics 105 No. 1 (February, 1990): 61-86.

Auerbach, Alan J., and Daniel Feenberg.

"The Significance of Federal Taxes as Automatic Stabilizers." Journal of Economic Perspectives 14 No. 3 (Summer, 2000): 3756.
Bond, Stephen R., and John Van Reenen.

"Microeconometric Models of Investment and Employment." In Handbook of Econometrics, edited by James J. Heckman and Edward E. Leamer, 4413-98. New York, NY: North Holland, 2007.

Devereux, Michael P.

"Tax Asymmetries, the Cost of Capital and Investment: Some Evidence from United Kingdom Panel Data." Economic Journal 99 No. 395, Supplement: Conference Papers (March, 1989): 103-12.

Devereux, Michael P., Michael Keen, and

Fabio Schiantarelli.

"Corporation Tax Asymmetries and Investment: Evidence from UK Panel Data." Journal of Public Economics 53 No. 3 (March, 1994): 395-418.

Fazzari, Steven M, R. Glenn Hubbard, and

Bruce C. Petersen.

"Financing Constraints and Corporate Investment." Brookings Papers on Economic Activity 19 No. 1(1988): 141-206. 
